\title{
Pseudohyperplastic Carcinoma of the Penis
}

National Cancer Institute

\section{Source}

National Cancer Institute. Pseudohyperplastic Carcinoma of the Penis. NCI Thesaurus.

Code C159245.

A multifocal, extremely differentiated squamous cell carcinoma of the penis. It typically occurs in older patients and is associated with lichen sclerosus. 